\title{
Method for Evaluating the Influence of Obstruction of Sea Breeze by Clusters of High-Rise Buildings on the Urban Heat Island Effect
}

\author{
Shota Sashiyama, Kayoko Yamamoto* \\ Graduate School of Information Systems, University of Electro-Communications, Tokyo, Japan \\ Email: ${ }^{*}$ k-yamamoto@is.uec.ac.jp
}

Received 2 June 2014; revised 29 June 2014; accepted 16 July 2014

Copyright (C) 2014 by authors and Scientific Research Publishing Inc.

This work is licensed under the Creative Commons Attribution International License (CC BY). http://creativecommons.org/licenses/by/4.0/

(c) ()

\section{Abstract}

This study aims to propose a method for quantitatively evaluating the influence which the obstruction of sea breezes by clusters of high-rise buildings has on the urban heat island effect using a weather simulation model and Geographic Information Systems (GIS). Specifically, a method of evaluating the influence of the obstruction of sea breeze by high-rise buildings on the urban heat island effect was proposed. In the method, two scenarios that imagine urban forms which differ with regard to whether or not they contain high-rise buildings are created and weather simulation is conducted, and the results of the simulations are comparatively analyzed focusing on temperature and wind speed. Evaluation was conducted in two stages, and Shiodome of Minato City in the Tokyo Metropolis was selected as the region for evaluation. In two stages of evaluation, a rise in temperature of approximately $0.3 \mathrm{~K}$ and a reduction in wind speed of approximately $1 \mathrm{~m} / \mathrm{s}$ were observed in a region approximately five to ten kilometers square downwind of high-rise buildings in the period $6 \mathrm{PM}$ to $9 \mathrm{PM}$, and a higher temperature caused by the obstruction of sea breeze by high-rise buildings was identified. The fact that such a higher temperature was confirmed in the time period from $6 \mathrm{PM}$ onwards, in which the temperature decreases, reveals that obstruction of sea breeze by high-rise buildings dulls the decrease in temperature which occurs from evening onwards, and influences nighttime urban heat island formation.

\section{Keywords}

Urban Heat Island Effect, Sea Breeze, Clusters of High-Rise Buildings, Weather Simulation Model, GIS

\footnotetext{
"Corresponding author.
}

How to cite this paper: Sashiyama, S. and Yamamoto, K. (2014) Method for Evaluating the Influence of Obstruction of Sea Breeze by Clusters of High-Rise Buildings on the Urban Heat Island Effect. Journal of Environmental Protection, 5, 983-996. http://dx.doi.org/10.4236/jep.2014.511099 


\section{Introduction}

According to the Ministry of the Environment (2013) [1], the global average temperature has risen by approximately $0.7^{\circ} \mathrm{C}$ over the past hundred years, and it is thought that global warming is the main cause. Meanwhile, in Tokyo, the capital of Japan, where urbanization has increased the most, the average temperature has risen by as much as approximately $3^{\circ} \mathrm{C}$ in the past hundred years. The fact that the temperature in Tokyo is rising more rapidly than the global average in this way is due to the fact that in addition to global warming, there is also the urban heat island effect. Therefore, in Japan, in order to mitigate the urban heat island effect, various efforts are being actively undertaken, and research inquiring into causes and mitigation effects is being actively conducted.

An example is that in recent years, the mitigating effects that cool sea breezes which flow into inland areas have on higher temperature areas are attracting attention. One such mitigation effect is achieved by building arrangement that is conscious of the path of wind. However, at the same time, it has also been pointed out that forests of high-rise buildings in coastal areas act like walls, and the flow of sea breezes into inland areas is obstructed. An example of an area where this happens is the Shiodome area in Tokyo. The urban heat island effect is the phenomenon of urban areas being higher in temperature than their surroundings, and sea breezes have a mitigating effect on the urban heat island effect; however, because clusters of high-rise buildings in coastal areas block sea breezes, higher temperatures are not mitigated, and heat islands form. However, until now, the influence that the obstruction of sea breezes by clusters of high-rise buildings has on the urban heat island effect has not been sufficiently understood.

Therefore, this study focuses on the issue that although higher temperatures should be mitigated by sea breezes flowing into inland areas, sea breeze flows are being obstructed by forests of high-rise buildings in coastal areas. Further, the aim of this study is to propose a method for quantitatively evaluating the influence which the obstruction of sea breezes by clusters of high-rise buildings has on the urban heat island effect using a weather simulation model and Geographic Information Systems (GIS).

\section{Related Work}

According to Nakagawa (2011) [2], research on the urban heat island effect has been carried out in Japan since the latter half of the 1960s. In the beginning, research mainly focused on the actual nature of the urban heat island effect and on quantitatively understanding the extent of the increase in temperature. For example, it was revealed that temperature cliffs exist in the vicinity of the boundary of urban and suburban areas. The mainstream of research in recent years is changing from research which places emphasis on clarifying the actual nature of the urban heat island effect and the main causes of its formation to research which aims to mitigate the urban heat island effect and improve amenities, by providing large-scale green spaces, greening rooftops, improving road paving and building materials, providing paths for wind and so on. However, research from the past has not lost its significance in recent years, and there are quite a number of issues which remain unresolved regarding clarification of the actual nature of the urban heat island effect and the main causes of its formation. For example, focusing on anthropogenic waste heat from road traffic, which is thought to be one of the main causes of the urban heat island effect, Imai et al. (2010) [3] used a GIS to evaluate measures concerning urban heat islands in the 23 wards of Tokyo in Japan. Grawe et al. (2012) [4] focused on London in the United Kingdom, and used numerical simulation to quantitatively grasp the influence that urbanization of land surface has on climate.

Concerning studies which have focused on the mitigating effect of sea breeze on higher temperatures, Taniguchi et al. (2008) [5] and Junimura et al. (2008) [6] used long-term temperature and wind observation data to understand the actual state of the mitigation of higher temperatures by sea breezes in Japan's urban regions and to understand the spatial distribution of the area covered by the mitigation effect. Yamato et al. (2011) [7] used observation data on temperature and wind in the Greater Tokyo Metropolitan area of Japan to examine the influence of sea breeze on the daytime urban heat island effect in summer. Wong et al. (2011) [8] focused on the Kowloon Peninsula in Hong Kong. From groups of buildings in the coastal area, they selected buildings which block sea breeze as being buildings which have a wall effect, and by conducting scenario analysis, they considered the influence which this has on the wind environment. Further, examples of representative preceding studies of recent years which focused on the influence of sea breeze on the urban heat island effect are Takebayashi et al. (2005) [9], Kiyota et al. (2005) [10], Sasaki et al. (2005) [11], Ooka et al. (2008) [12], Nobayashi et al. (2009) [13] and Sakaida et al. (2011) [14].

The above-mentioned previous studies confirmed the mitigating effect of sea breezes on areas of higher tem- 
peratures, and revealed that this influences the urban heat island effect. Meanwhile, it has also been pointed out that in areas where under normal circumstances higher temperatures would be mitigated by the inflow of sea breeze, the mitigating effect is not exercised because clusters of high-rise buildings block the inflow of sea breeze, and urban heat islands are formed. However, the above-mentioned studies did not clarify in specific terms what kind of effect clusters of high-rise buildings obstructing the inflow of sea breezes has on the urban heat island effect.

Therefore, this study is unique in that it focuses on the obstruction of the inflow of sea breezes by clusters of high-rise buildings and proposes a method of evaluating the influence of this on the urban heat island effect. Further, this study is useful in that it proposes a very versatile evaluation method which can be applied to many cities located on the coast. In the evaluation method of this study, using a weather simulation model and a GIS, attention is focused on the relation of clusters of high-rise buildings with the extent of rises in temperature, the positional relationship of clusters of high-rise buildings with regions where the temperature is higher and so on. Further, based on data on land use, landform and climate, the influence which the obstruction of sea breeze by clusters of high-rise buildings has on the urban heat island effect is quantitatively evaluated.

\section{Evaluation Method}

\subsection{Outline of Evaluation}

Firstly, in Section 4, data is collected and some data is processed in line with the data format of the simulation model. Next, in Section 5, based on the various sets of data collected and processed in the previous section, as the first stage of evaluation, evaluation of all the periods of time subject to evaluation is conducted, focusing on whether or not areas of higher temperature caused by obstruction of sea breeze can be confirmed. In section 6 , as the second stage of evaluation, based on the evaluation results from the first stage, attention is focused on periods of time in which sea breeze can be confirmed. So that the situation regarding the obstruction of sea breeze by clusters of high-rise buildings is better reflected, simulation is conducted after part of the simulation model has been changed, and more detailed evaluation is carried out.

\subsection{Weather Simulation Model Selection}

In this study, simulation was conducted focusing on a wide area; therefore, the WRF (Weather Research and Forecasting) Model, which is a mesoscale model, was selected. The WRF is a weather model whose development is being advanced jointly by organizations such as the National Center for Atmospheric Research (NCAR) and the National Centers for Environmental Prediction (NCEP) in the USA. The WRF allows simulation domain range and resolution to be set to suit the research aim, and through the use of a canopy model, allows the influence of buildings on the land surface to be analyzed in more detail. The WRF is starting to be widely used in weather and climate research of recent years. Core versions of WRF are the NMM (Nonhydrostatic Mesoscale Model), whose main purpose is weather forecasting, and the ARW (Advanced Research WRF), whose main purpose is academic research. In this study, based on Kusaka (2009, 2011) [16] [17], the WRF-ARW Ver. 3.3.1 was used. Further, the WPS (WRF Preprocessing System) is available as software for preparing data for executing the WRF, such as initial conditions and boundary conditions. The WPS can be used to input and edit data to set simulation domains. When working using WPS, intermediate files are created at each stage of work, so by editing these files, input data and so on can be changed and updated.

\subsection{Evaluation Method}

In this study evaluation was conducted in two stages, according to the flow shown in Figure 1. Firstly, two scenarios which imagined different urban forms - one with high-rise buildings and the other without high-rise buildings-were created. Using Scenario 1, a simulation which imagined a fictitious urban form in which there were no high-rise buildings at all and only low rise buildings were distributed was conducted, and results were obtained for a weather simulation in which the influence of high-rise buildings was not reflected. Using Scenario 2 , a simulation of a realistic urban form in which there was a mixture of high-rise and low-rise buildings was conducted, and results were obtained for a weather simulation in which the influence of high-rise buildings was reflected. Next, the simulation results for the two scenarios were comparatively analyzed.

The outline of the evaluation method is as follows. In both the first and second stages of the evaluation, a GIS 


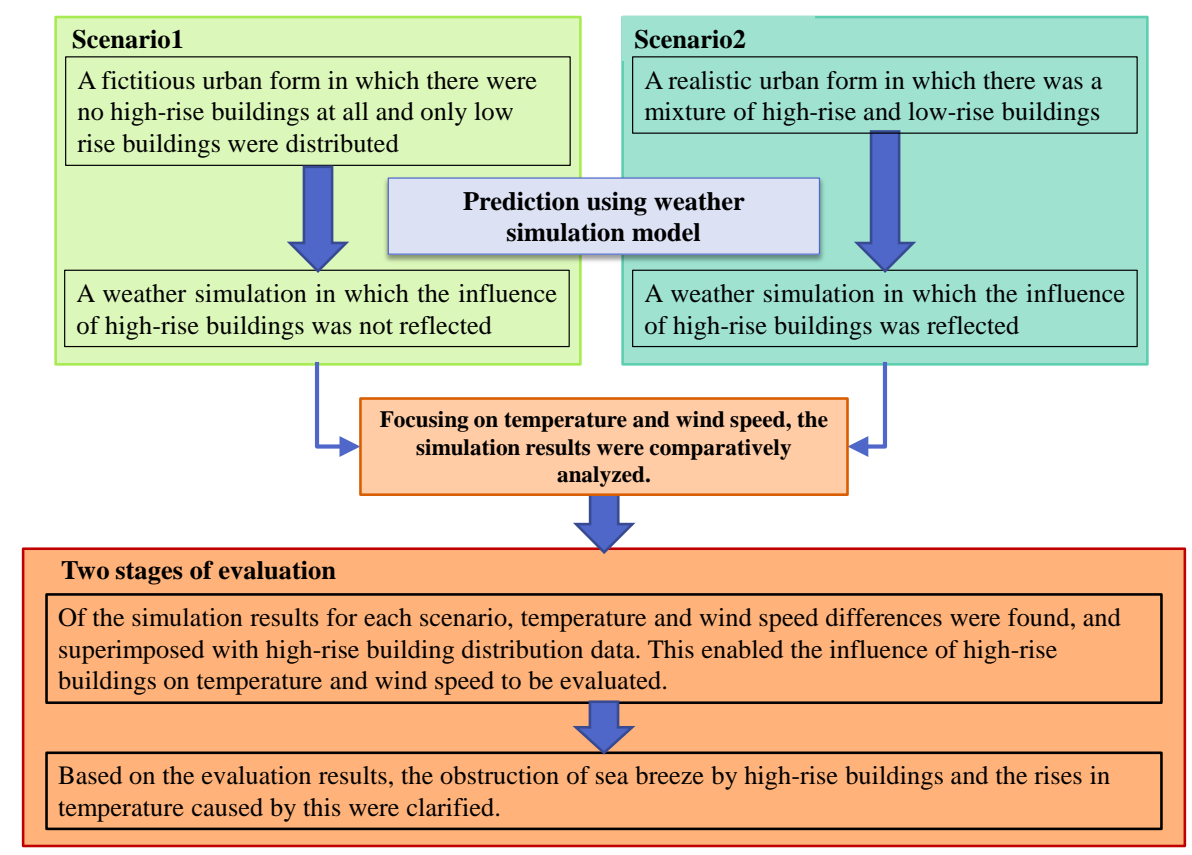

Figure 1. Evaluation flow.

was used to display simulation results for Scenarios 1 and 2 which were obtained using the WRF on digital maps, and the simulation results were comparatively analyzed. Further, as the GIS, ESRI Inc.'s ArcGIS ver. 10.2 was used.

1) In the first stage, all the periods of time subject to evaluation were evaluated. Simulations for all the time periods subject to evaluation were conducted for each of the two scenarios; focusing on temperature and wind speed, the simulation results were comparatively analyzed; and influence to the urban heat island effect was evaluated. Specifically, of the simulation results for each scenario, temperature and wind speed differences were found, and superimposed with high-rise building distribution data. This enabled the influence of high-rise buildings on temperature and wind speed to be evaluated. Further, based on the comparative analysis results, conditions for conducting more detailed evaluation in the second stage of evaluation were clarified.

2) In the second stage of evaluation, simulations were conducted for each of the two scenarios, reflecting the conditions for conducting detailed evaluation which were found in the first stage of evaluation. Next, as in the first stage, these simulation results were comparatively analyzed, and comparison was made with evaluation results from the first stage. This enabled the influence of high-rise buildings on temperature and wind speed to be evaluated. Based on the evaluation results, the obstruction of sea breeze by high-rise buildings and the rises in temperature caused by this were clarified.

\subsection{Selection of Region and Periods of Time for Evaluation}

As the region for evaluation in this study, a region thirty kilometers square centering on Shiodome of Minato City in the Tokyo Metropolis was selected. Reasons for selection were that in this region, there is a concentration of clusters of high-rise buildings on the coast of Tokyo Bay, and in guidelines published by Japan Meteorological Agency (2013) [18], it is pointed out that clusters of high-rise buildings are influencing the wind environment in this region. Concerning the periods of time for evaluation, taking the aim of this study into consideration, August 7th from the record-breaking heat wave of July to August 2010 was selected as a date that satisfied all the undermentioned conditions of fine weather days and sea breeze days defined by Kitao et al. (2012) [15] .

1) Fine weather days:

- The weather is fine or sunny (The average degree of cloudiness is 8.4 or less)

- There are seven or more hours of sunlight

- The daily amount of accumulated global solar radiation is $19 \mathrm{MJ} / \mathrm{m} 2$ or more

- The amount of precipitation is less than $0.5 \mathrm{~mm}$ 
2) Sea breeze days:

- In the 12 hours between midday and midnight, the wind speed is $2 \mathrm{~m} / \mathrm{s}$ or more and there is a sea breeze for six hours or more.

Further, the weather data used in the simulations which employ the WRF are data for six hour intervals for 3 AM, 9 AM, 3 PM and 9 PM Japan time. Because it is necessary to make these times the start and finish times of the simulations, the specific period of time for which simulation was conducted was 3 AM on August 7th, 2010 to 3 AM on August 8th, 2010 (Japan Standard Time).

\section{Data Collection and Processing}

\subsection{Data Collection}

In weather simulations which use the WRF, land cover data, constructed from land use data and landform data and weather data, such as atmospheric data and sea surface temperature, are necessary. In the WRF, as default data, for land cover data, data from the US Geological Survey (USGS) is input; and as weather data, objective analysis data from the NCEP (FNL: Global Final Analyses) is input. Besides these sets of default data, in Japan, land use data from the Geospatial Information Authority of Japan can be used as land use data, and meso objective analysis data (MANAL: Meso-Scale Analysis) from the Japanese Meteorological Agency can be used as weather data. Akimoto et al. (2010) [19] showed that by using land use data from the Geospatial Information Authority of Japan instead of data from the USGS, calculation results that more closely match observed values can be obtained in Japan. Therefore, in this study, as weather data and landform data, the WRF default data, that is, FNL and USGS data, were used; and as land use data, based on Akimoto et al. (2010) [19], urban area land use subdivided mesh data for 2009 from the Geospatial Information Authority of Japan was used.

\subsection{Data Processing}

Urban area land use subdivided mesh data from the Geospatial Information Authority of Japan was processed according to the following procedure:

(1) There are 27 categories of land use in the WRF; however, the above-mentioned urban area land use subdivided mesh data has 11 categories, and its method of classifying land use is different to that of the WRF. Therefore, with reference to Akimoto et al. (2010) [19], the land use categories in the urban area land use subdivided mesh were made to correspond to the unique categories of the WRF, as shown in Table 1. Further, in Scenario 1, which does not divide buildings into low-rise buildings and high-rise buildings, both types of buildings were classified as "Low Intensity Residential". In Scenario 2, which divides buildings into low-rise buildings and high-rise buildings, low-rise buildings were classified as "Low Intensity Residential", and high-rise buildings were classified as "High Intensity Residential". This work was performed using the ArcGIS field calculation function, and the processed land use data was output in CSV file form. Urban forms in Scenarios 1 and 2 in the region for evaluation are shown in Figure 2.

Further, when working with the WRF, it is necessary to create variables which show whether surfaces in the simulation domain are water surfaces or land surfaces. Therefore, ArcGIS was used to create data in which land uses which correspond to "Water Bodies" in Table 1 were classified as water surfaces, and land uses other than these were classified as land surfaces. This data was also output in CVS file form.

(2) Using the WPS, values for the variable LU_INDEX (which shows land use) and values for the variable LANDMASK (which shows the state of the surface) in the intermediate files of the simulation domains created using the USGS land cover data were substituted with values from the CSV files output in Step (1), described above, and simulation domains which reproduced the land use of each scenario were created. Similarly, using the WPS, the weather data was also input into the simulation domains, and files for input into the WRF were created.

(3) Using an application for the creation of WRF boundary files, vertical boundary data was input into the files for input into the WRF that were created in Step (2), described above. At this time, the variable IVGTYP, which shows vegetation of land surface, was newly added. Values for this variable should have been the same as those for LU_INDEX; however, when the data created for input into the WRF was checked, it was found that some of the LANDMASK values had changed into values different to those used for substitution in Step (2) above. Therefore, the values which differed were corrected by being once again replaced with the CSV file values output in Step (1). 
Table 1. Correspondence list of land use classification.

\begin{tabular}{|c|c|c|}
\hline \multirow{2}{*}{ Land use classification for WRF } & \multicolumn{2}{|c|}{ Urban area land use subdivided mesh data } \\
\hline & Scenario 1 & Scenario 2 \\
\hline \multirow[t]{2}{*}{ Urban and built-up land } & Road & Road \\
\hline & Railway & Railway \\
\hline Dryland, cropland and pasture & - & - \\
\hline Irrigated cropland and pasture & Rice field & Rice field \\
\hline Mixed dryland/Irrigated cropland and pasture & - & - \\
\hline Cropland/Grassland mosaic & Wasteland & Wasteland \\
\hline Cropland/Woodland mosaic & - & - \\
\hline \multirow[t]{4}{*}{ Grassland } & Other farmlands & Other farmlands \\
\hline & Golf course & Golf course \\
\hline & Open space & Open space \\
\hline & Park and greenery area & Park and greenery area \\
\hline Shrubland & - & - \\
\hline Mixed shrubland/Grassland & - & - \\
\hline Savanna & - & - \\
\hline Deciduous broadleaf forest & - & - \\
\hline Deciduous needleleaf forest & - & - \\
\hline Evergreen broadleaf forest & - & - \\
\hline Evergreen needleleaf forest & - & - \\
\hline Mixed forest & Forest & Forest \\
\hline \multirow[t]{3}{*}{ Water bodies } & River and lake & River and lake \\
\hline & Seashore & Seashore \\
\hline & Sea & Sea \\
\hline Herbaceous wetland & - & - \\
\hline Wooded wetland & - & - \\
\hline Barren of sparsely vegetated & - & - \\
\hline Herbaceous tundra & - & - \\
\hline Wooded tundra & - & - \\
\hline Mixed tundra & - & - \\
\hline Bare ground tundra & - & - \\
\hline Snow or ice & - & - \\
\hline \multirow[t]{3}{*}{ Low intensity residential } & Low intensity residential & Low residential \\
\hline & Low intensity residential (crowded) & Low intensity residential (crowded) \\
\hline & High intensity residential & - \\
\hline High intensity residential & - & High intensity residential \\
\hline \multirow[t]{2}{*}{ Industrial of commercial } & Factory & Factory \\
\hline & Public facilities & Public facilities \\
\hline
\end{tabular}

\section{Evaluation of All the Periods of Time Subject to Evaluation}

\subsection{Post-Processing of Simulation Results}

Simulation results for wind direction and wind speed were illustrated using the GIS. Using the WRF, wind direction and wind speed can be calculated as scalar quantities for each simulation domain grid cell, based on the east-west direction ( $\mathrm{x}$ component) wind speed and the north-south direction (y component) wind speed, as shown below.

1) Calculation of wind speed

Wind speed is expressed by the magnitude of a vector formed from an x component and a y component. Therefore, it can be found using the following equation:

$$
\text { Wind speed }=\sqrt{x^{2}+y^{2}}
$$

2) Calculation of wind direction

Wind direction can be found as a gradient $\theta$ of a vector in a mathematical $\mathrm{x}-\mathrm{y}$ plane, as shown in Figure 3. 

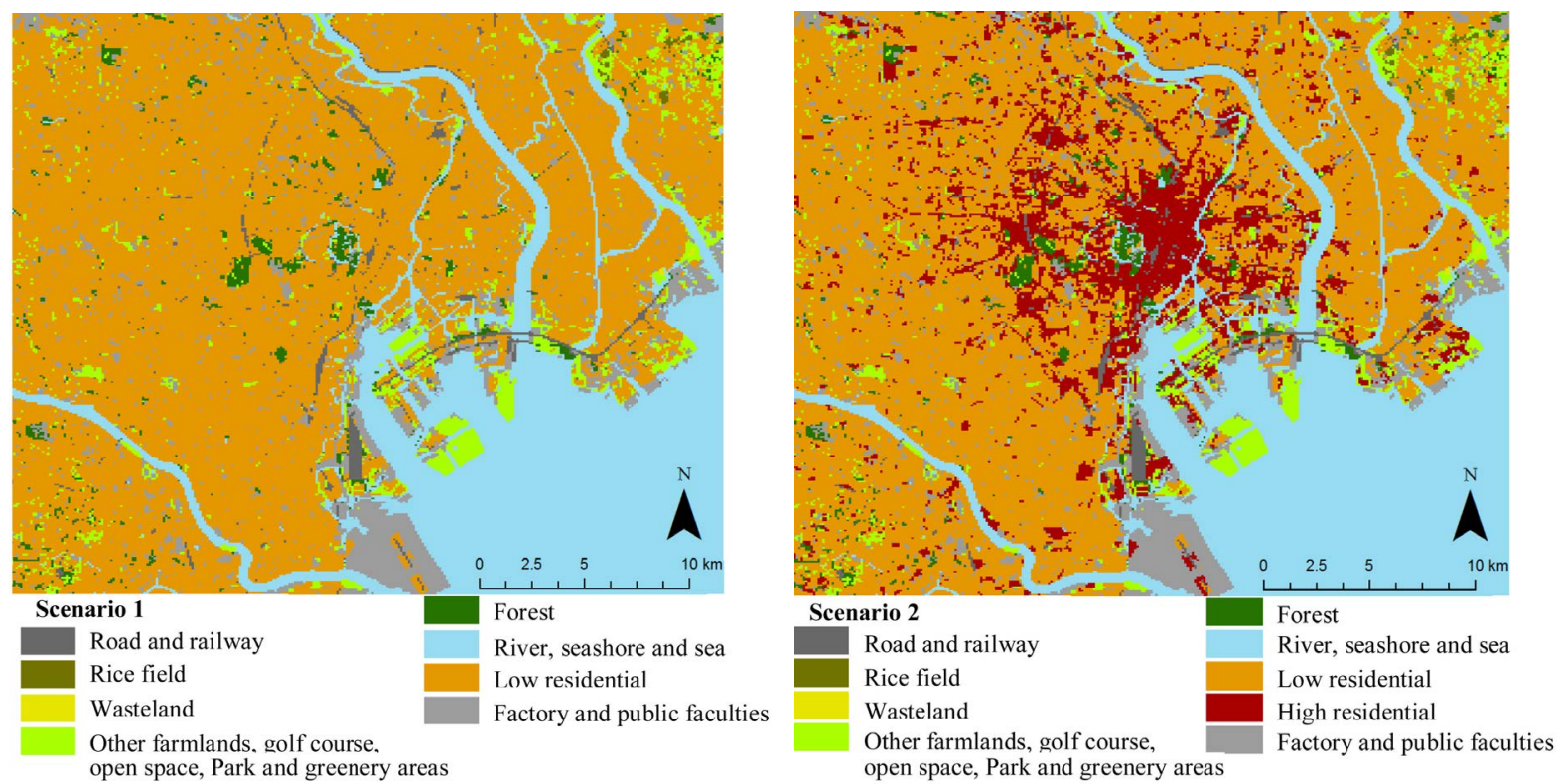

Figure 2. Urban forms in Scenarios 1 and 2 in the region for evaluation.

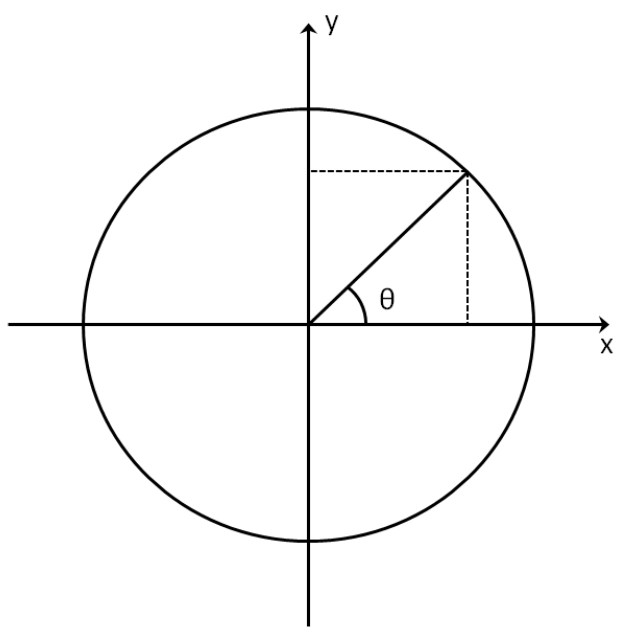

Figure 3. Calculation of wind direction.

The gradient can be found using the inverse trigonometric function arctan; however, the range of $\theta$ calculated using $\arctan$ is $\pi / 2 \geq \theta \geq-\pi / 2$, and not all the gradients of the range can be obtained. Therefore, using the atan 2 function of the mathematical problem solver library of the programming language Python, which is included in the ArcGIS ver. 10.2, the gradient was found using the following equation:

$$
\theta=a \tan 2(y / x)
$$

Sasaki et al. (2005) [11], Kitao et al. (2012) [15] and Grawe et al. (2012) [4] conducted simulation using a grid with grid cell intervals of several kilometers. Similarly to these previous studies, in this study, based on simulation results output for each $100 \mathrm{~m}$ interval grid cell, average values for each $1 \mathrm{~km}$ interval grid cell were found and resampled in order to derive the wind direction.

3) Calculation of temperature differences and wind speed differences between Scenarios 1 and 2

Further, in order to compare the simulation results of Scenarios 1 and 2, differences in temperature and wind speed between Scenarios 1 and 2 were also found for each $1 \mathrm{~km}$ interval grid cell. As in studies by Taniguchi et al. (2008) [5] and Junimura et al. (2008) [6], the difference in wind speed was derived as a scalar quantity. 


\subsection{Simulation Results for Each Hour}

In the evaluation for all the periods of time subject to evaluation, simulation results were organized for each hour from 4 AM to midnight. Figure 4 shows wind direction and wind speed for Scenario 2 (the scenario with a realistic urban form in which there is a mixture of high-rise buildings and low-rise buildings) for 6 AM to 9 AM. From 4 AM to 6 AM the wind was not a sea breeze; however, as shown in Figure 4, after a calm period from 7 $\mathrm{AM}$ to $8 \mathrm{AM}$, the wind direction changed and the wind became a sea breeze, and it was possible to confirm a sea breeze from about 9 AM to 9 PM. Further, in Figure 5, temperature differences and wind speed differences between Scenarios 1 and 2 from 7 PM to 9 PM are each superimposed with the distribution of high-rise buildings. As will be described in detail in the next section, in this time period it was possible to confirm a rise in temperature and a reduction in wind speed in a region downwind of high-rise buildings.

\subsection{Discussion}

Simulation results for Scenario 1 (which had an imaginary urban form which did not include high-rise buildings), and Scenario 2 (which had a realistic urban form which included a mixture of high-rise buildings and low-rise buildings) were comparatively analyzed, focusing on temperature difference and wind speed difference. In the analysis, the influence of high-rise buildings on temperature and wind speed was evaluated by showing how temperature and wind speed increased and decreased in Scenario 2 in relation to Scenario 1, based on differences in temperature and wind speed between Scenarios 1 and 2, as illustrated in Figure 5.

From 9 AM to 6 PM, both increases and decreases in wind speed caused by high-rise buildings were detected. Regions where wind speed dropped and rose were located in no particular pattern in the inland area. Further, regions where increases in temperature occurred were sparsely located in the inland area, and the degree of the
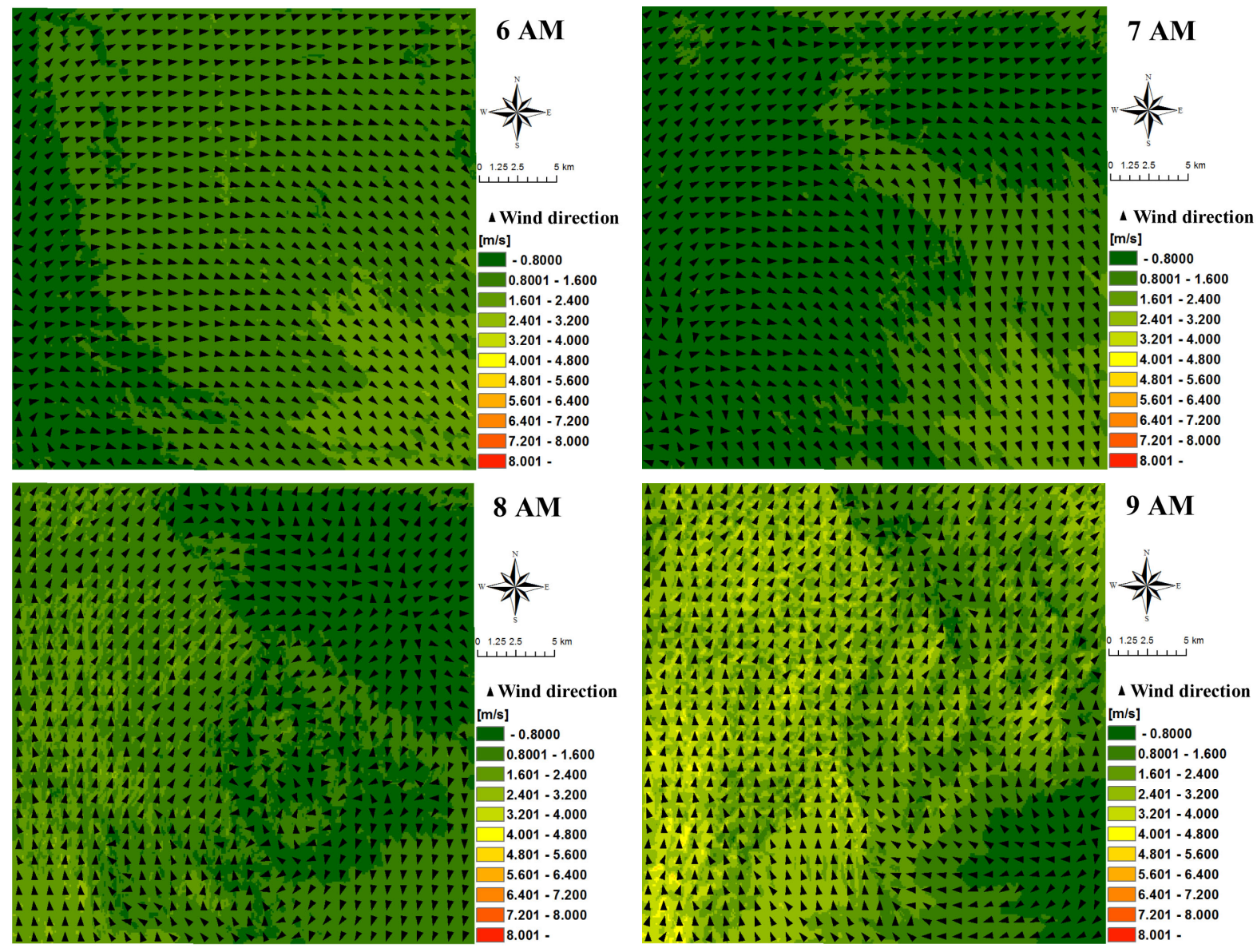

Figure 4. Wind direction and wind speed for Scenario 2 for 6 AM to 9 AM. 

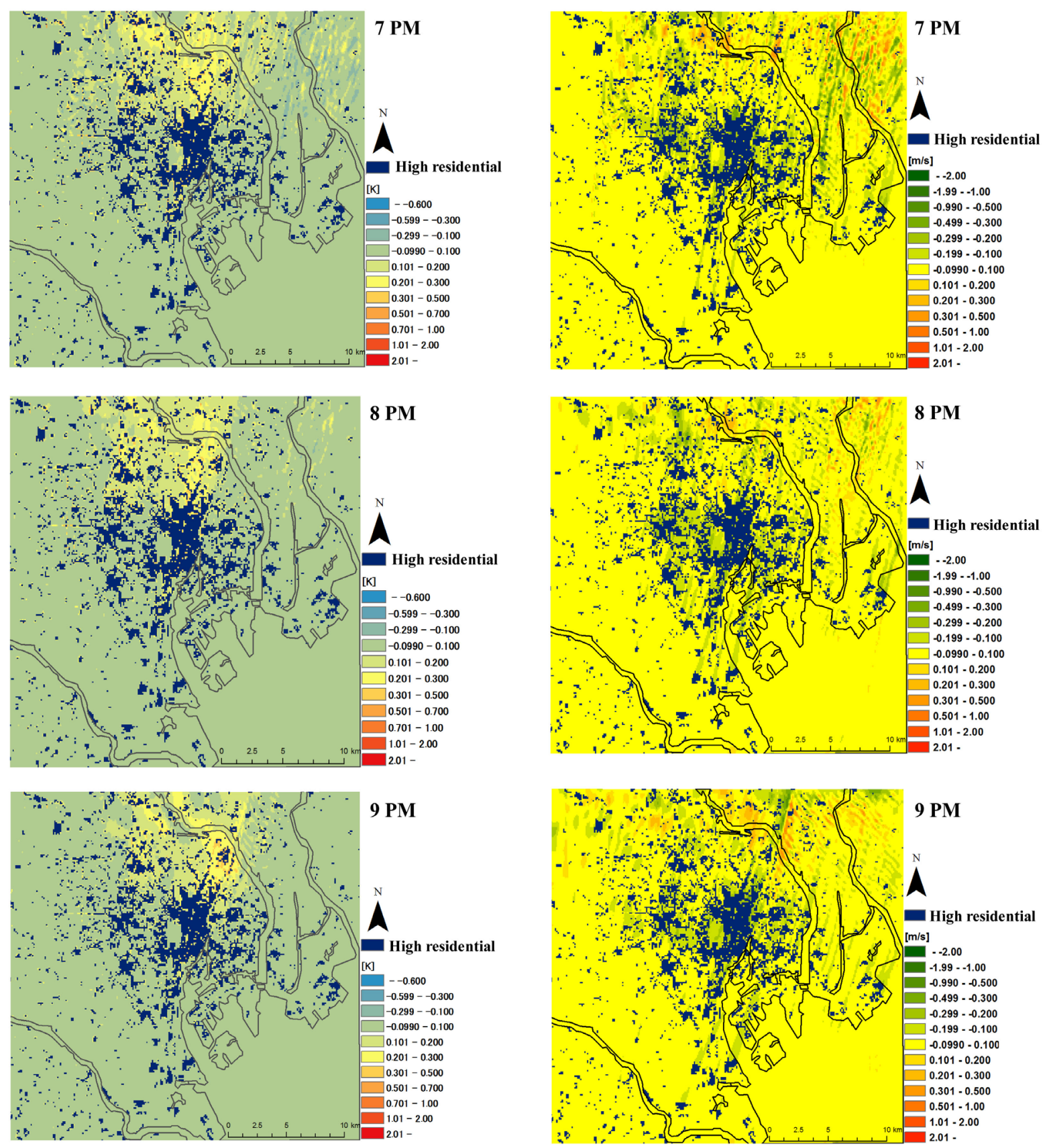

Figure 5. Temperature differences (left side) and wind speed differences (right side) between Scenarios 1 and 2 from 7 PM to 9 PM.

increase in temperature was from 0.2 to $1 \mathrm{~K}$. However, because regions where wind speed dropped and regions where warming occurred were not necessarily the same, it is difficult to say that increases in temperature were caused by the obstruction of sea breeze by high-rise buildings. However, as shown in Figure 5, an increase in temperature of about $0.2 \mathrm{~K}$ was confirmed in the time period $7 \mathrm{PM}$ to $9 \mathrm{PM}$ in a region of 5 to $10 \mathrm{~km}$ square downwind of high-rise buildings. Meanwhile, there were regions where the wind speed dropped in a region 2 $\mathrm{km}$ square downwind of high-rise buildings, but compared to regions of higher temperature, their range was very small. Therefore, it can be said that in a region $2 \mathrm{~km}$ square downwind of high-rise buildings where a rise in temperature and a reduction in wind speed were confirmed, a higher (by about $0.2 \mathrm{~K}$ ) temperature occurred due to the obstruction of sea breeze. Mikami (2005) [20] pointed out that the rise in temperature caused by urba- 
nization alone in Tokyo has been about $2 \mathrm{~K}$ over the past hundred years. From the above-mentioned simulation results of this study, it is clear that the rise in temperature due to obstruction of sea breeze by high-rise buildings is about $0.2 \mathrm{~K}$, which is equivalent to about $10 \%$ of the rise in temperature caused by urbanization.

Changes in wind speed that were due to the presence or absence of high-rise buildings were confirmed in many of the time periods between 4 AM and midnight. However, wind speed differences in the period $10 \mathrm{AM}$ to 5 PM were confirmed regardless of the presence or absence of high-rise buildings. Further, from 6 PM onwards, there is a region where a decrease in wind speed occurred downwind of high rise buildings, so it was possible to confirm obstruction of sea breeze by high-rise buildings; however, the range of this area is smaller than that of the region where there was a rise in temperature. Therefore, it is considered that the influence of high-rise buildings on wind speed was not sufficiently reproduced by the simulation. Considering the simulation results in more detail, the height of high-rise buildings in the urban canopy model introduced into the WRF is originally set at $7.5 \mathrm{~m}$, whereas the calculated values for wind speed output by the WRF are values for $10 \mathrm{~m}$ above the ground. Therefore, it is thought that the influence of high-rise buildings on wind speed was not sufficiently shown in the simulation results in this section. Accordingly, it was thought that if the urban canopy model parameters were changed such that the height of high-rise buildings was $10 \mathrm{~m}$ or more, obstruction of sea breeze would show up more clearly in the simulation results. Therefore, in the next section, high-rise building height is set at $10 \mathrm{~m}$, and the time period $7 \mathrm{PM}$ to $9 \mathrm{PM}$, in which sea breeze was confirmed in this section, is evaluated in detail.

\section{Evaluation of Time Periods in Which Sea Breeze Occurred}

\subsection{Simulation Results}

Based on the results in the previous section, all conditions were made the same as in the previous section, except for high-rise building height, which was changed to $10 \mathrm{~m}$, and simulation was conducted for the period 9 AM to 9 PM. Figure 6 shows wind speed differences between Scenarios 1 and 2 for 6 PM in the first stage of the evaluation (described in the previous section) and the second stage of the evaluation (described in this section). From Figure 6, it can be seen that setting the high-rise building height to $10 \mathrm{~m}$ resulted in the influence of high-rise buildings on wind showing more clearly in the simulation results of this section than it did in the simulation results of the previous section. Further, in Figure 7, temperature differences and wind speed differences between Scenarios 1 and 2 for the time period 6 PM to 9 PM are each superimposed with high-rise building distribution. As is described in detail below, it was possible to confirm higher temperatures caused by obstruction of sea breeze by high-rise buildings in this time period.

\subsection{Discussion}

For the time period 9 AM to $9 \mathrm{PM}$, as in the previous section, simulation results for Scenarios 1 and 2 were comparatively analyzed, and comparison with evaluation results from the previous section was conducted. In the comparative analysis of simulation results for Scenarios 1 and 2, as in Section 5.3, the influence of high-rise buildings on temperature and wind speed was evaluated by showing how temperature and wind speed increased and decreased in Scenario 2 in relation to Scenario 1, based on differences in temperature and wind speed between Scenarios 1 and 2, as illustrated in Figure 7.

Firstly, in the time period $1 \mathrm{PM}$ to $4 \mathrm{PM}$, there is a region containing a mixture of increases and decreases in wind speed; however, it was confirmed that the wind speed decreases in approximately the same region as the region where high-rise buildings are located. Further, in the time period 5 PM to 9 PM, concerning a decrease in wind speed that was barely identifiable in the simulation results of the previous section, as shown by the results for 7 PM to 9 PM in Figure 6, in the simulation results of this section it became possible to confirm decreases in wind speed in a region of high-rise buildings and a region downwind of high-rise buildings. These results show that setting the high-rise building height to $10 \mathrm{~m}$ allowed the influence of high-rise buildings on wind speed to be reflected in the simulation results, and it was revealed that sea breeze was obstructed in a region of high-rise buildings and a region downwind of high-rise buildings.

When the height of high-rise buildings was set to $10 \mathrm{~m}$ in the evaluation in this section, the result was a decrease in the range of the region containing a mixture of increases and decreases in wind speed in the time period $9 \mathrm{AM}$ to $4 \mathrm{PM}$; however, the region still existed, as in the evaluation of the previous section. The existence of turbulence is a possible reason for regions with a mixture of increases and decreases in wind speed occurring 

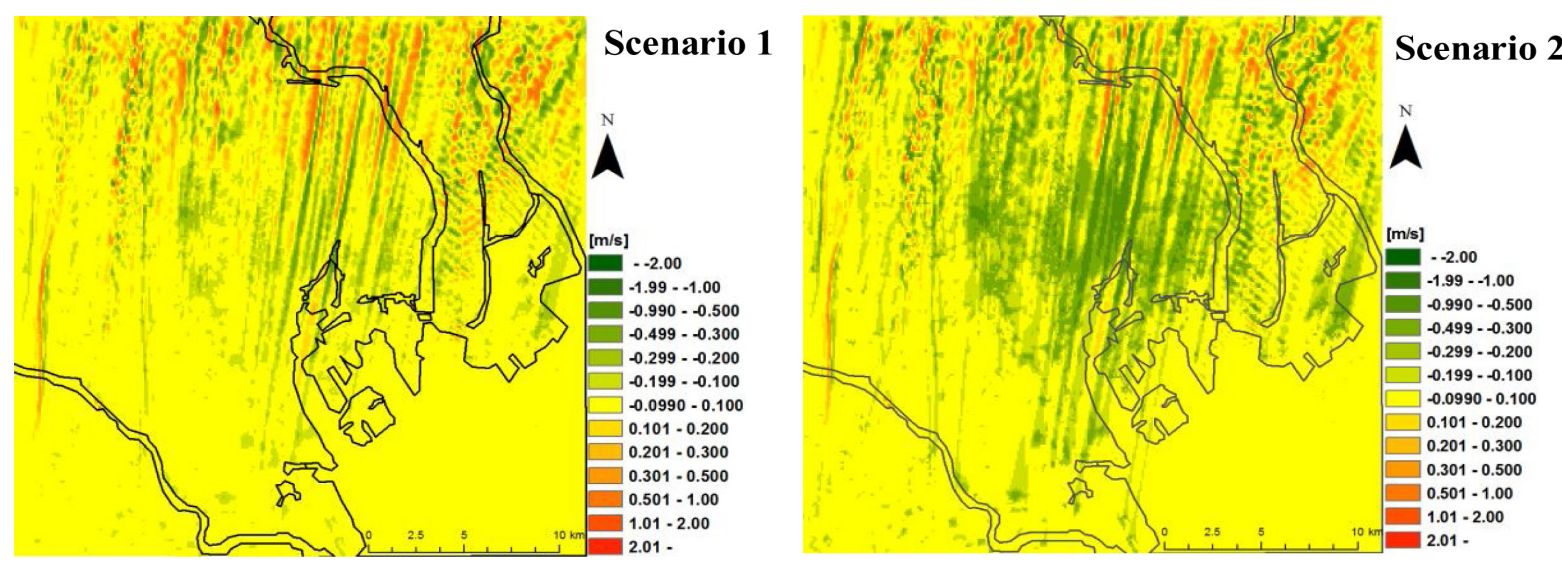

Figure 6. Wind speed differences between Scenarios 1 and 2 for 6 PM in the first stage of the evaluation.
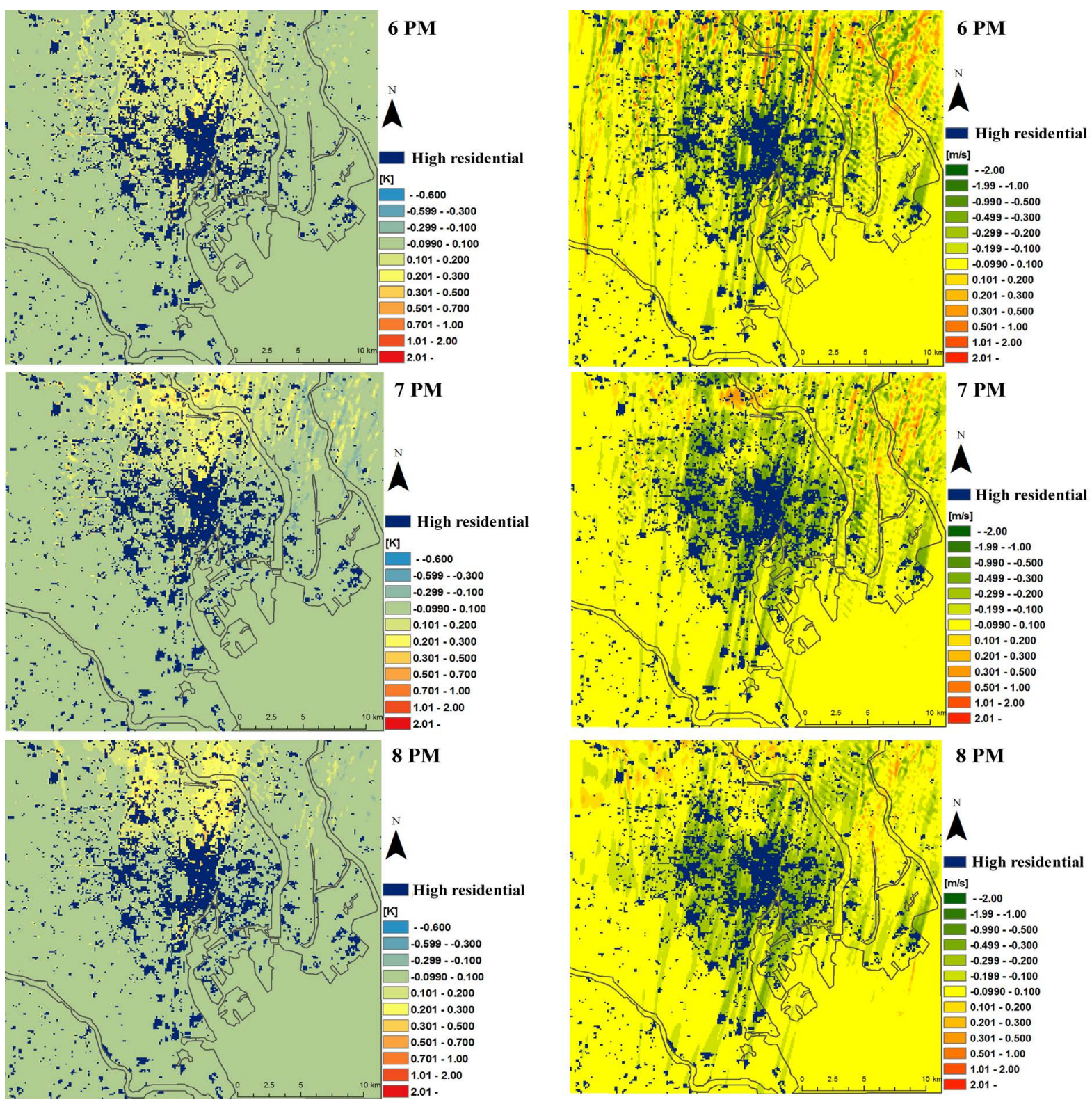

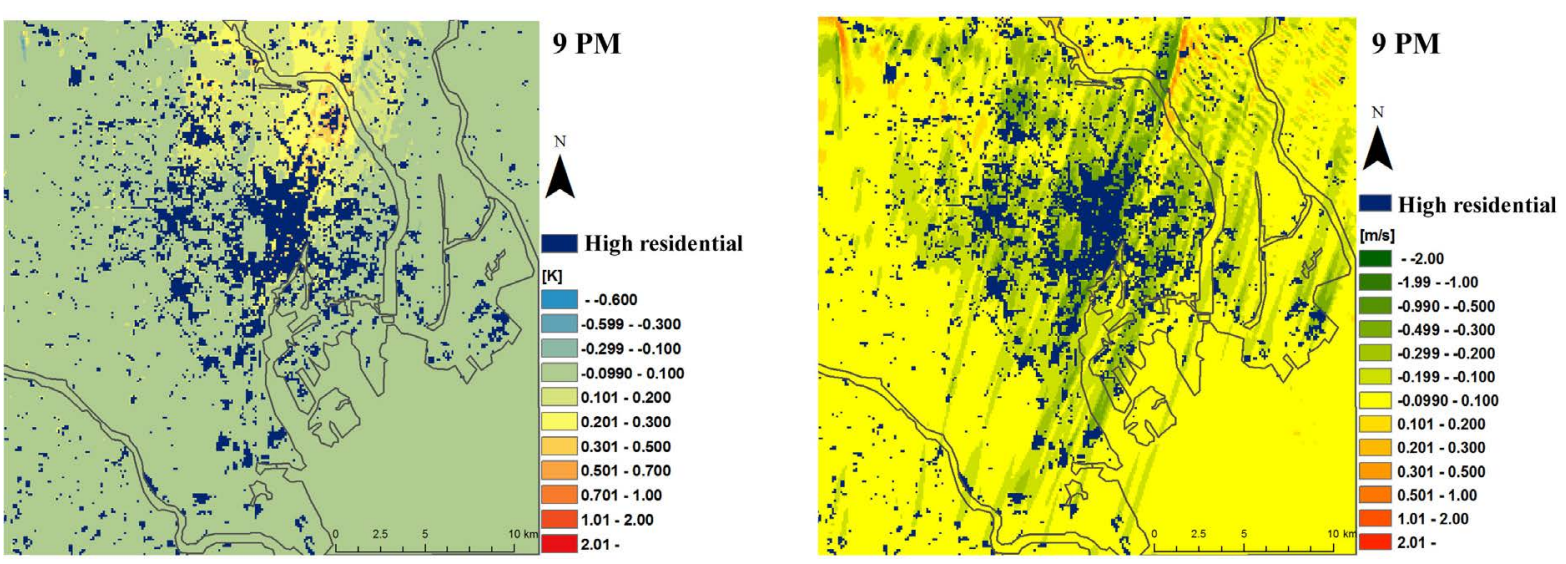

Figure 7. Temperature differences (left side) and wind speed differences (right side) between Scenarios 1 and 2 from $6 \mathrm{M}$ to 9 PM.

in this manner. Turbulence is a type of state of a fluid flow field. Almost all air currents in the atmospheric boundary layer are also turbulence. Examples of characteristics of turbulence given by Takeuchi (1997) [21] are that it is a three-dimensional flow, it has vortex motion, and it has a large diffusing capacity. It is thought that due to turbulence, which has three-dimensional vortex motion, in some regions a flow of air (wind) that goes upwards occurs, and in other regions a flow of air that goes downwards occurs. There is a negative correlation between vertical wind speed and horizontal wind speed. When the wind flows upwards, horizontal wind speed decreases, and when the wind flows downwards, horizontal wind speed increases. This shows that fast-flowing wind from an upper region is descending, and slow-flowing wind from a lower region is ascending. Physically speaking, the momentum of wind is being conveyed from above to below. This is termed "momentum transport" (Kondou, 2000) [22]. Therefore, it is thought that vertical winds occur due to high-rise buildings intensifying turbulence; that horizontal wind speed decreases in regions where the wind flows upwards and increases in regions where the wind flows downwards; and that in regions with high-rise buildings, there is a mixture of these two types of region.

At $5 \mathrm{PM}$ in a region with a wind speed lower by about $2 \mathrm{~m} / \mathrm{s}$, it was confirmed the temperature was higher by about $0.3 \mathrm{~K}$. From 6 PM to 9 PM the decrease in wind speed was about $1 \mathrm{~m} / \mathrm{s}$; however, the range of the area where the wind speed decreased spread further. In conjunction with this, the temperature was higher by about $0.2 \mathrm{~K}$ over a wide range. Since a decrease in wind speed and a higher temperature were confirmed at the same time over a wide range in this manner, it is clear there is a relationship between decrease in wind speed and higher temperatures. Therefore, it is thought that in the region where it was possible to confirm a decrease in wind speed and a higher temperature at the same time during 5 PM to 9 PM, a higher temperature caused by obstruction of sea breeze by high-rise buildings occurred, and it occurred over an area of five to ten kilometers square.

As described above, in the period of time subject to evaluation in this section, it was possible to confirm a higher temperature caused by obstruction of sea breeze during the period 5 PM to $9 \mathrm{PM}$. In the period 9 AM to 4 PM, decreases and increases in wind speed thought to have been caused by turbulence were confirmed, and in these areas there were also areas of higher temperature; therefore, it is difficult to say that the higher temperatures occurred due to obstruction of sea breeze by high-rise buildings in the period 9 AM to 4 PM. During this period of time, the temperature on land was high, at $304.6 \mathrm{~K}$ or more, and wind speed was on the rise. However, in the period 5 PM to 9 PM, the temperature continued to decrease from 5 PM onwards, and wind speed continued to decrease from 6 PM onwards. After 5 PM to 6 PM, during which warming caused by obstruction of sea breeze by buildings can be confirmed, temperature and wind speed were on the decline. As the temperature decreased from 5 PM onwards, it became possible to confirm higher temperatures caused by obstruction of sea breeze; therefore, it is thought that although normally, the temperature on land should cool down due to the inflow of sea breeze, an area of higher temperature occurred due to sea breeze being blocked in a region downwind of high-rise buildings. Therefore, it is clear that rather than impeding the suppression of increases in daytime temperature, the obstruction of sea breeze by high-rise buildings weakens the decrease in temperature which occurs from evening onwards, and contributes to the formation of nighttime urban heat islands. 


\section{Conclusion and Future Research Topics}

The conclusion of this study can be summarized into the following three points:

1) A method of evaluating the influence of the obstruction of sea breeze by high-rise buildings on the urban heat island effect was proposed. In the method, two scenarios that imagine urban forms which differ with regard to whether or not they contain high-rise buildings are created and weather simulation is conducted, and the results of the simulations are comparatively analyzed focusing on temperature and wind speed. Evaluation was conducted in two stages, and Shiodome of Minato City in the Tokyo Metropolis was selected as the region for evaluation. In the first stage, the influence of high-rise buildings on temperature and wind speed was evaluated in all the periods of time subject to evaluation, and conditions for conducting more detailed evaluation were found. In the second stage, based on the conditions clarified in the first stage, the influence of high-rise buildings on temperature and wind speed was evaluated in detail, and the obstruction of sea breeze by high-rise buildings and the higher temperature that is caused by this were revealed.

2) The first stage of evaluation revealed that during the period of time subject to evaluation, sea breeze could be confirmed from 9 AM to 9 PM. Further, a rise in temperature of approximately 0.2 K caused by the obstruction of sea breeze was confirmed in an area two kilometers square downwind of high-rise buildings. In addition, the first stage of evaluation revealed the necessity of setting the height of high-rise buildings in the weather simulation model to suit present conditions of urban regions in Japan, and conducting detailed evaluation in the second stage of evaluation.

3) In the second stage of evaluation, a rise in temperature of approximately $0.3 \mathrm{~K}$ and a reduction in wind speed of approximately $1 \mathrm{~m} / \mathrm{s}$ were observed in a region approximately five to ten kilometers square downwind of high-rise buildings in the period 6 PM to 9 PM, and a higher temperature caused by the obstruction of sea breeze by high-rise buildings was identified. The fact that such a higher temperature was confirmed in the time period from 6 PM onwards, in which the temperature decreases, reveals that obstruction of sea breeze by high-rise buildings dulls the decrease in temperature which occurs from evening onwards, and influences nighttime urban heat island formation.

Examples of future research themes are to apply the evaluation method proposed in this study to other regions and periods of time and verify its validity, and to check detailed changes in temperature and wind speed by conducting weather simulation using shorter intervals of time.

\section{References}

[1] Japanese Ministry of the Environment (2013) Urban Heat Island Countermeasures Guideline for the Year 2012-Revised Edition. http://www.env.go.jp/air/life/heat_island/guideline/h24.html

[2] Nakagawa, K. (2011) Trends in Studies on the Formative Factors of the Urban Heat Island in Japan, with Special Emphasis on the Formative Factors of Urban Heat Island Intensity. Journal of Geography, 120, 255-284. http://dx.doi.org/10.5026/jgeography.120.255

[3] Imai, K. and Yamamoto, K. (2010) An Evaluation of Measures against the Urban Heat Island from the Viewpoint of Artificial Exhaust Heat of Road Traffic: An Evaluation Using GIS in the Tokyo 23-Ward Area. Japan Society of Socio-Informatics Journal, 21, 47-58.

[4] Grawe, D., Thompson, H.L., Salmond, J.A., Cai, X.M. and Schlünzen, K.H. (2012) Modelling the Impact of Urbanisation on Regional Climate in the Greater London Area. International Journal of Climatology, 33, 2388-2401. http://dx.doi.org/10.1002/joc.3589

[5] Taniguchi, A., Kiyota, N. and Kiyota, T. (2008) Study on Mitigation Effect of Sea Wind for High Temperature Phenomenon in Urban Area in Coastal City. Journal of Environmental Engineering (Transactions of AIJ), 73, 379-384. http://dx.doi.org/10.3130/aije.73.379

[6] Junimura, Y. and Watanabe, H. (2008) Study on the Mitigating Effects of Sea Breeze on Urban Temperatures in Summer-Analyses Based on Long-Term Multi-Point Simultaneous Observation of Temperature and observed Wind Data-. Journal of Environmental Engineering (Transactions of AIJ), 73, 93-99. http://dx.doi.org/10.3130/aije.73.93

[7] Yamato, H., Mikami, T. and Takahashi, H. (2011) Influence of Sea Breeze on the Daytime Urban Heat Island Effect in Summer in the Greater Tokyo Metropolitan Area. Journal of Geography, 120, 325-340. http://dx.doi.org/10.5026/jgeography.120.325

[8] Wong, M.S., Nichol, J. and Ng, E. (2011) A Study of the "Wall Effect” Caused by Proliferation of High-Rise Buildings Using GIS Techniques. Landscape and Urban Planning, 102, 245-253.

http://dx.doi.org/10.1016/j.landurbplan.2011.05.003 
[9] Takebayashi, H. and Moriyama, M. (2005) Urban Heat Island Phenomena Influenced by Sea Breeze. AIJ Journal of Technology and Design, 21, 199-202.

[10] Kiyota, T. and Kiyota, N. (2005) A Study on Influence of Land And Sea Breeze on Air Temperature in the Greater Hiroshima Area in Summer. Journal of Environmental Engineering (Transactions of AIJ), 45-51.

[11] Sasaki, K., Mochida, A., Yoshino, H., Watanabe, H. and Yoshida, T. (2005) Comparison of Atmospheric Heat Balance Mechanisms in Central Parts of Three Pacific Cities of Differing Scale, Tokyo, Sendai, and Haramachi, on Fine Summer Days When Sea Breezes Prevail-Quantification of Regional Characteristics of Urban Climate Based on Climatic Numerical Analysis (No.1). Journal of Environmental Engineering (Transactions of AIJ), 121-128.

[12] Ooka, R., Satou, T. and Murakami, S. (2008) Mesoscale Numerical Analysis of Penetration of Sea Breeze into Inland Areas and Quantification of Factors in Obstruction of Sea Breeze Based on Mean Kinetic Energy Balance Analysis. Journal of Environmental Engineering (Transactions of AIJ), 73, 1201-1207. http://dx.doi.org/10.3130/aije.73.1201

[13] Nobayashi, A. and Hayashi, Y. (2009) Observational Study on Effect of Dynamical Mixing on Small-Scale Heat Islands. Bulletin of the Terrestrial Environment Research Center, the University of Tsukuba, 75-81.

[14] Sakaida, K., Egoshi, A. and Kuramochi, M. (2011) Urban Heat Islands and the Effects of Sea Breezes in Sendai. Journal of Geography, 120, 382-391. http://dx.doi.org/10.5026/jgeography.120.382

[15] Kitao, N., Moriyama, M., Takebayashi, H. and Tanaka, T. (2012) Study on Method for Creating an Urban Environment Climate Map for the Osaka Region. AIJ Journal of Technology and Design, 18, 255-258. http://dx.doi.org/10.3130/aijt.18.255

[16] Kusaka, H. (2009) The Regional Atmospheric Model WRF. Journal of Japan Society of Fluid Mechanics, 3-12.

[17] Kusaka, H. (2011) Application of the Regional Atmospheric Model WRF to Urban Climate Study and Future Issues. Journal of Geography, 120, 285-295. http://dx.doi.org/10.5026/jgeography.120.285

[18] Japan Meteorological Agency (2013) Heat Island Monitoring Report (2012). 158 p.

[19] Akimoto, Y. and Kusaka, H. (2010) Sensitivity of the WRF Regional Meteorological Model to Input Datasets and Surface Parameters for the Kanto Plain on Fine Summer Days. Geographical Review of Japan, 83, 324-340. http://dx.doi.org/10.4157/grj.83.324

[20] Mikami, T. (2005) Urban Heat Island Phenomena and their Causing Factors : A Case Study of Tokyo Metropolis. Journal of Geography, 114, 496-506. http://dx.doi.org/10.5026/jgeography.114.3_496

[21] Takeuchi, K. (1997) Meteorology of the Wind. University of Tokyo Press, Tokyo, 131 p.

[22] Kondou, J. (2000) Atmospheric Science near the Ground Surface. University of Tokyo Press, Tokyo, 82-84. 